\title{
DISSEMINAÇÃO DE SALMONELLA NO PROCESSAMENTO INDUSTRIAL EM PEQUENA ESCALA DE SALAME ARTESANAL
}

\section{(Dissemination of Salmonella in small-scale artisanal salami production)}

\author{
Juliano Gonçalves Pereira1', Vinicius Cunha Barcellos², Luciano dos Santos Bersot². \\ "Universidade Estadual Paulista "Júlio de Mesquita Filho", Faculdade de Medicina Veterinária e

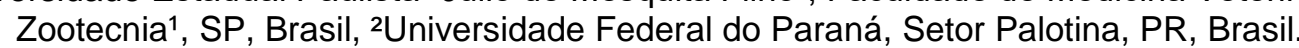

1'Autor para correspondência: juliano.pereira@unesp.br

RESUMO - O objetivo deste estudo foi avaliar a disseminação de Salmonella no processamento de salame artesanal. Foram selecionados seis diferentes pontos do fluxograma de produção de uma planta de processamento de pequeno porte e coletadas 20 amostras de diferentes lotes para a realização das análises microbiológicas, totalizando 120 amostras. Todas as amostras foram submetidas à pesquisa de Salmonella e NMP de coliformes a $35^{\circ} \mathrm{C}$ e $45^{\circ} \mathrm{C}$, com exceção dos condimentos, onde foi pesquisada apenas a presença do patógeno. Além disso, nas amostras coletadas após a defumação, foi aferido o $\mathrm{pH}$. Durante o processo de produção, a contaminação por coliformes decresceu e Salmonella foi isolada em todos os pontos do fluxograma, com exceção da carcaça. O ponto onde houve maior número de amostras positivas foi após a cura (35\%). Amostras de condimentos e salames após o embutimento apresentaram $20 \%$ de positividade e a carne logo após a moagem e o produto final apresentaram $10 \%$ e $5 \%$, respectivamente. Verificou-se que houve a disseminação do patógeno durante a produção de salame e este fato ocorreu principalmente por falhas no processamento do alimento além de procedimentos inadequados de higienização utilizados durante as operações de produção, sendo esta etapa fundamental para a obtenção de alimentos com qualidade microbiológica e que não ofereçam riscos de veiculação de patógenos.

Palavras-chave: contaminação; embutidos; patógenos.

ABSTRACT - The aim of this study was to evaluate the dissemination of Salmonella in small-scale traditional salami production. Six different points of salami processing plant were selected and 20 samples of differents batchs were collected for the microbiological analyzes, totaling 120 samples. All samples were submitted to coliforms $35^{\circ} \mathrm{C}$ and $45^{\circ} \mathrm{C}$ counts by MPN and Salmonella detection, except for condiments, where only the presence of the pathogen was investigated. In addition, in the samples collected after smoking the $\mathrm{pH}$ was measured. During the salami production, the coliform counts decreased and Salmonella was isolated at all points in the flow chart with the exception of the carcass. The point where there was the high contamination was after healing (35\%). Samples of condiments and salami after inlay presented $20 \%$ positivity and ground meat and final product presented $10 \%$ and $5 \%$, respectively. It was verified that there was the dissemination of the pathogen during the production of salami and this fact occurred mainly due to failures in the food processing besides inadequate procedures of hygiene used during the production operations, being this fundamental step to obtain foods with microbiological quality and which do not pose risks of pathogen transmission.

Keywords - contamination; pathogens; sausages. 


\section{INTRODUÇÃO}

O salame produzido em pequenas indústrias da região Sul do Brasil tem como características ser um produto embutido cru composto por carnes suína e/ou bovina, de fermentação natural e defumado. A fermentação natural é uma identidade marcante deste produto, não havendo adição de culturas iniciadoras, sendo responsável pelo processo fermentativo apenas a microbiota autóctone do produto bem como das mãos dos manipuladores e do ambiente industrial. $\mathrm{O} \mathrm{pH}$ baixo, atividade de água reduzida e a adição de sais de cura (nitrito e nitrato), são fatores que limitam a multiplicação de micro-organismos patogênicos, tornando os embutidos fermentados produtos de baixo risco microbiológico e, consequentemente, seguros para o consumo (Toldra, 2017; Sanz-Perea et al., 2018).

No entanto, mesmo com a combinação de fatores antimicrobianos, deve se considerar a possibilidade de sobrevivência de micro-organismos patogênicos, uma vez que este produto não sofre nenhum tipo de tratamento térmico. Quando presentes em níveis elevados, a população bacteriana pode ser reduzida durante a fermentação e maturação, mas pode persistir no produto final e ter a capacidade de, mesmo com uma baixa contagem microbiana, causar uma infecção alimentar. Diversos estudos têm demonstrado a presença de patógenos em embutidos fermentados, sendo Salmonella frequentemente isolada nestes tipos de produtos, uma vez que sua distribuição é ubiquitária, estando distribuída no ambiente de processamento de carnes (Gottardo et al., 2011; Kuhn et al., 2011; Martin et al., 2011; Zocche et al., 2011; Andreoli et al., 2017; Bonardi et al., 2017).

A contaminação por Salmonella durante a produção de salames pode ocorrer em todas as etapas da produção. A alta prevalência da contaminação de carcaças de suínos durante o processo de abate (Silva et al., 2009; Schwarz et al., 2009, Kich et al., 2011; Colello et al., 2018) pode ser uma das explicações para a presença deste patógeno no produto final, além disso, a intensa manipulação e utilização de equipamentos e utensílios higienizados inadequadamente podem servir como fontes de contaminação. $O$ consumo antes do período ideal de maturação também tem sido relatado como fator desencadeante de surtos causados pela ingestão de salames (Luzzi et al., 2007). Outro fator que pode levar a contaminação do produto final é a utilização de condimentos contaminados com Salmonella (Moreira et al., 2009; Zhang et al., 2017, Chitrakar et al., 2018).

Baseado nestas considerações, o objetivo deste estudo foi avaliar a ocorrência e disseminação de Salmonella durante a produção em pequena escala de salame artesanal.

\section{MATERIAL E MÉTODOS}

Coleta e preparo das amostras

Foram selecionados seis diferentes pontos do fluxograma de produção de salames em uma pequena indústria localizada no Oeste do Estado do Paraná, como descrito no Quadro 1.

Foi realizado o acompanhamento da produção de 20 lotes distintos produzidos em diferentes dias. De cada lote, foi realizada a coleta de amostras nos seis pontos do fluxograma (Quadro 1), o que totalizou 120 amostras. De todos os pontos foram coletadas quantidades de amostras suficientes para a pesagem posterior, com exceção da carcaça, onde foram coletados swabs superficiais da parte interna e externa numa área total de $50 \mathrm{~cm}^{2}$. Todo o procedimento de coleta foi realizado de forma asséptica e as unidades amostrais mantidas em sacos 
plásticos estéreis e em recipiente isotérmico até o momento das análises.

As pesagens e diluições das amostras seguiram o preconizado pelo por Bacteriological Analytical Manual (BAM, 2016), sendo, posteriormente, submetidas à contagem de coliformes a $35^{\circ} \mathrm{C}$ e $45^{\circ} \mathrm{C}$ pela técnica do Número Mais Provável e pesquisa e identificação de Salmonella.

Quadro 1 - Pontos de coleta de amostras na linha de produção de salame.

\begin{tabular}{cl}
\hline Identificação & $\begin{array}{l}\text { Ponto de coleta na linha de } \\
\text { produção }\end{array}$ \\
\hline P1 & $\begin{array}{l}\text { Superfície de carcaça na } \\
\text { câmara fria antes da desossa e } \\
\text { moagem }\end{array}$ \\
P2 & $\begin{array}{l}\text { Carne imediatamente após a } \\
\text { moagem }\end{array}$ \\
P3 & $\begin{array}{l}\text { Condimentos antes da adição } \\
\text { ao produto; }\end{array}$ \\
P4 & Salame após o embutimento \\
P5 & Salame após a cura \\
P6 & Salame após a defumação \\
\hline
\end{tabular}

\section{Análises microbiológicas}

Número Mais Provável de coliformes a $35^{\circ} \mathrm{C}$ e $45^{\circ} \mathrm{C}$

Após a pesagem e diluições, alíquotas foram semeadas em série de três tubos contendo $9 \mathrm{~mL}$ do Caldo Lauril Sulfato Triptose (LST) e incubados por 48 horas a $35^{\circ} \mathrm{C}$. Após este período, foram retiradas alíquotas de LST que apresentaram reação positiva (turvação do meio e formação de gás) e semeadas em Caldo Bile Verde Brilhante $2 \%$ e em Caldo Escherichia coli, sendo incubados a $35^{\circ} \mathrm{C}$ e $45^{\circ} \mathrm{C}$ por período de 48 horas, respectivamente. Os tubos com turvação do meio e produção de gás foram considerados positivos e o resultado foi expresso em $\mathrm{NMP} / \mathrm{g}$ de coliformes a $35^{\circ} \mathrm{C}$ e $45^{\circ} \mathrm{C}$ de acordo com tabela específica (Brasil, 2003).
Pesquisa de Salmonella.

Alíquotas das amostras (25 g) e swabs foram pré-enriquecidos em água peptonada tamponada a 1\% (APT) e incubados a $35^{\circ} \mathrm{C}$ por 24 horas. Da mistura pré-enriquecida, foram transferidos $0,1 \mathrm{~mL}$ e $1 \mathrm{~mL}$ para tubos contendo $10 \mathrm{~mL}$ do caldo RappaportVassiliadis (RV) e $10 \mathrm{~mL}$ de caldo Tetrathionato (TT), respectivamente. Os caldos RV e TT foram incubados por $42^{\circ} \mathrm{C} / 24$ horas e $35^{\circ} \mathrm{C} / 24$ horas, respectivamente. A partir dos caldos de enriquecimento seletivo, foram realizadas estrias em placas com ágar Sulfito de Bismuto (BS) e ágar XiloseLisina-Desoxicolato (XLD) sendo incubadas por 24 horas a $35^{\circ} \mathrm{C}$. As colônias típicas em BS e XLD foram repicadas para tubos de Lisina Iron Agar (LIA) e Triple Sugar Iron Agar (TSI) e incubados a $35^{\circ} \mathrm{C}$ por 24 horas. A partir dos tubos que apresentaram crescimento característico de Salmonella, testes bioquímicos (ureia, indol, vermelho de metila, VogesProskauer e citrato) e sorológicos (soro polivalente) foram realizados para a confirmação da presença de Salmonella (BAM, 2016).

\section{Sorotipificação de Salmonella}

A identificação sorológica dos isolados de Salmonella foi realizada no laboratório de Enterobacteriaceae da Fundação Oswaldo Cruz (FIOCRUZ), Rio de Janeiro, Brasil.

\section{Análise físico-química - $p H$}

Amostras de salame (P6) foram fragmentadas em pequenos pedaços e depositadas em um béquer. A seguir, foram adicionados $50 \mathrm{~mL}$ de água destilada e realizada a aferição do $\mathrm{pH}$ em pHmêtro de acordo com Brasil (2017). 


\section{RESULTADOS E DISCUSSÃO}

Pela Tabela 1, é possível observar que as amostras, tanto da matéria-prima quanto do produto final, apresentaram contaminação considerável de coliformes a $35^{\circ} \mathrm{C}$ e $45^{\circ} \mathrm{C}$, sendo observada uma redução nas amostras coletadas logo após a defumação, porém, mesmo após este processo, o salame apresentou média de NMP de coliformes a $45^{\circ} \mathrm{C}(3,34 \mathrm{log}$ $\mathrm{NMP} / \mathrm{g}$ ) acima do estabelecido pela ANVISA, (Brasil, 2001). Um ponto importante que pode explicar a diminuição das contagens de coliformes, é o baixo valor de $\mathrm{pH}$ atingido no produto final $(4,66)$. A fermentação causada por micro-organismos autóctones da carne é responsável pela queda no $\mathrm{pH}$ obtida no salame pronto para o consumo. Essa queda de $\mathrm{pH}$, que funciona como barreira de proteção para o desenvolvimento microbiano pela interferência no metabolismo celular bacteriano, não foi suficiente para reduzir as contagens de coliformes à níveis aceitáveis. Coliformes são grupos de micro-organismos distribuídos no ambiente e importantes indicadores de contaminação em alimentos, desta forma, altas contagens podem indicar baixa qualidade de matérias-primas ou falhas higiênicas durante a manipulação e processamento da carne para a produção de salame.

Cabe ressaltar que, devido à produção em pequena escala, a fermentação obtida nos salames avaliados foi feita de forma natural, não tendo sido adicionados culturas iniciadoras (starters), como é frequente na produção em escala industrial. A fermentação iniciada por starters, rara de ocorrer em salames produzidos de maneira artesanal, fornece maior segurança microbiológica ao produto, por promover uma queda de $\mathrm{pH}$ controlada. Contudo, quando comparado com estudos que utilizaram starters para a fermentação, os resultados de $\mathrm{pH}$ foram muito semelhantes (Ellajosyula et al., 1998; Nightingale et al., 2006).

Com relação à pesquisa de Salmonella, em todos os pontos do fluxograma foi observada a presença do patógeno, com exceção das amostras coletadas das carcaças suínas (P1). Apesar dos suínos servirem como fonte de contaminação por Salmonella no ambiente industrial e dados da literatura demonstrarem que a prevalência na carcaça suína pode variar de 0 a $20 \%$ (Hald et al., 2003; EFSA, 2008), nenhuma das carcaças avaliadas foi positiva para Salmonella.

Pode-se dizer que as falhas no processo de higienização dos equipamentos e utensílios foram importantes na contaminação do produto já que logo após a moagem (P2) o patógeno foi encontrado, observando a presença de dois sorotipos de Salmonella (Newport e Panama). Práticas inadequadas de higienização de equipamentos e superfícies podem permitir a sobrevivência de micro-organismos, servindo como fonte constante de contaminação para os produtos no ambiente industrial, como observado por Reij et al. (2004). Alguns autores suportam a ideia de que a prevalência de patógenos em salames acabados é derivada da matéria-prima cárnea contaminada e do próprio ambiente de manipulação (Gounadaki et al., 2008; Martin et al., 2011) e um estudo realizado por Gormley et al. (2010) demonstraram a persistência de um sorotipo de Salmonella durante em vários lotes de embutidos, sugerindo um processo de higienização industrial deficiente. 
Tabela 1 - Média do Número Mais Provável de coliformes à $35^{\circ} \mathrm{C}$ e $45^{\circ} \mathrm{C}$, frequência de Salmonella e sorotipos identificados.

\begin{tabular}{|c|c|c|c|c|}
\hline $\begin{array}{l}\text { Ponto do } \\
\text { fluxograma }\end{array}$ & $\begin{array}{l}\text { Coliformes } \\
35^{\circ} \mathrm{C}\end{array}$ & $\begin{array}{l}\text { Coliformes } \\
45^{\circ} \mathrm{C}\end{array}$ & Salmonella & Sorotipos de Salmonella \\
\hline $\mathrm{P} 1(\mathrm{n}=20)$ & $4,24 !$ & 3,291 & $0 / 20(0 \%)$ & $\mathrm{ND}$ \\
\hline P2 $(n=20)$ & 4,33 & 3,90 & $2 / 20(10 \%)$ & Newport; Panama \\
\hline P3 $(n=20)$ & NR & NR & $4 / 20(20 \%)$ & $\begin{array}{l}\text { Brandenburg; } S \text {. enterica } \\
\text { subsp enterica }(4,5---)\end{array}$ \\
\hline$P 4(n=20)$ & 4,83 & 4,03 & $4 / 20(20 \%)$ & $\begin{array}{l}\text { Newport; Panama; } \\
\text { S.enterica subsp enterica } \\
(4,5:--)\end{array}$ \\
\hline P5 $(n=20)$ & 4,73 & 4,20 & $7 / 20(35 \%)$ & $\begin{array}{l}\text { Brandenburg; Newport; } \\
\text { Ohio; Panama; } \\
\text { Thyphimurium; S. enterica } \\
\text { subsp enterica (rugosa); S } \\
\text { enterica subsp enterica } \\
(9,12:--)\end{array}$ \\
\hline$P 6(n=20)$ & 3,75 & 3,34 & $1 / 20(5 \%)$ & Newport \\
\hline
\end{tabular}

${ }^{1} \mathrm{NMP} / \mathrm{cm}^{2}, \mathrm{NR}=$ Não realizada, $\mathrm{ND}=$ Não foi detectado Salmonella

No ponto 3, foram analisados os condimentos utilizados na formulação dos salames. De acordo com a Tabela $1,20 \%$ das amostras de condimentos foram positivas para Salmonella e os sorotipos isolados neste ponto foram Brandenburg e $S$. enterica subesp enterica sorotipo 4,5:-:-. A presença de Salmonella em condimentos usados na elaboração do salame no estabelecimento avaliado confirma 0 que foi observado por outros estudos, que demonstraram que condimentos (principalmente pimentas) utilizados na formulação de embutidos, podem servir de fonte de diversos micro-organismos patogênicos (Sospedra et al., 2010), entre eles Salmonella (Moreira et al., 2009; Sagoo et al., 2009; Zhang et al., 2017) e até mesmo como fonte de contaminação em casos de surtos de doenças veiculadas por alimentos (Zweifel \& Stephan, 2011).

Outra questão é que após a condimentação e embutimento (P4), houve um aumento no número de amostras positivas para Salmonella, passando de 10\% em P2 (carne após a moagem) para $20 \%$ em P4, demonstrando que após a condimentação houve um incremento na contaminação. Outro fator que pode explicar o aumento no número de amostras positivas é a contaminação cruzada proporcionada pela não higienização correta dos equipamentos. Neste ponto, os sorotipos de Salmonella isolados já tinham sido isolados em P2 e P3, demonstrando a persistência destes sorotipos no fluxo de processamento. A contaminação cruzada é definida como a transferência de micro-organismos para um alimento anteriormente não contaminado via superfícies, equipamentos ou mãos de manipuladores e ocorre devido a falhas nos procedimentos de higiene préoperacional e operacional dentro das indústrias de alimentos (Carrasco et al., 2012).

Dos pontos avaliados, amostras que foram coletadas após a cura (P5) apresentaram maior frequência de positividade para Salmonella (35\%). Por esse resultado, é possível observar que o processo de cura de 72 horas e a temperatura da câmara de cura $\left(2^{\circ} \mathrm{C}\right)$ não foram suficientes para a manutenção da segurança dos salames, pelo contrário, durante 0 período de cura, provavelmente houve uma adaptação do patógeno sendo possível o seu isolamento em um número maior de amostras.

Diversos estudos demonstraram uma redução da frequência de isolamento de Salmonella após processo de fermentação por períodos de 24-72 horas (Ellajosyula et al., 1998, Nightingale et al., 2006), fato não observado no presente estudo. A capacidade de suportar $\mathrm{pH}$ abaixo de 5,0 pode explicar a alta porcentagem de amostras positivas, além disso, a negligência com os procedimentos de higienização pode ter influenciado no aumento significativo de amostras 
contaminadas com Salmonella. Com relação aos sorotipos, além dos já isolados em ponto anteriores, foram verificados ainda a presença dos sorotipos Ohio, Typhimurium, $S$. enterica subesp enterica (rugosa); $S$. enterica subesp enterica 9,12:-:-.

Após a defumação (P6), houve uma diminuição das amostras positivas, neste ponto, apenas um salame (5\%) apresentou contaminação por Salmonella (sorotipo Newport) além da diminuição das contagens de coliformes a $35^{\circ} \mathrm{C}$ e $45^{\circ} \mathrm{C}$. A ação combinada do calor e da fumaça reduz eficazmente a população bacteriana da superfície do produto, pois a superfície defumada se converte em uma barreira química e física bastante eficaz frente ao crescimento e penetração de microorganismos, devido à desidratação, coagulação das proteínas e deposição de material resinoso por condensação dos formaldeídos e fenóis derivados da fumaça, resultando numa maior conservação do produto após este processo (Toldra, 2017). Contudo, há de se considerar a presença do sorotipo Newport no produto final uma vez que este é um dos principais sorotipos envolvidos em surtos em diversos países. Nos Estados Unidos, surtos causados por este sorotipo ocorreram em 2018 (333 pessoas envolvidas em 28 estados), 2017 (quatro pessoas envolvidas em quatro estados) e 2015 (363 pessoas envolvidas em 43 estados) (CDC, 2019).

Dos isolados de Salmonella, foram identificados oito sorotipos diferentes (Tabela 1). Este resultado é importante, pois demonstrou que a contaminação por diversos sorotipos na linha de produção avaliada é um indicativo de origens distintas de contaminação. O ponto 5 foi o que demonstrou uma maior variedade de sorotipos ( 7 dos 8 encontrados ao longo do processo de produção). Apesar da escassez de dados que demonstrem os diversos sorotipos de Salmonella em embutidos, alguns estudos demostram a relação destes sorotipos com a carne suína. Em estudo realizado em Santa Catarina - Brasil, Kich et al. (2011) demonstraram que Typhimurium foi 0 mais prevalente em suínos, seguido do sorotipo Panama, sendo este último, considerado um sorotipo mais invasivo para crianças podendo levar a morte por meningite, como relatado por Chen et al. (2005) e Choudhury et al. (2006). Kich et al. (2007) e Schwarz et al. (2009), também obtiveram os mesmos resultados, demonstrando que Panama e Typhimurium foram os sorotipos mais isolados em suínos.

\section{CONCLUSÃO}

Embora no produto final apenas uma amostra tenha sido positiva, deve ser ressaltado que durante a produção houve a disseminação do patógeno e que este fato ocorreu principalmente por falhas no processamento do alimento além de inadequados procedimentos de higienização utilizados durante as operações de produção, sendo esta etapa fundamental para a produção de alimentos com qualidade microbiológica e que não ofereçam riscos de veiculação de patógenos.

\section{REFERÊNCIAS}

ANDREOLI, G.; MERLA, C.; VALLE, C.D. et al. Foodborne Salmonellosis in Italy: Characterization of Salmonella enterica Serovar Typhimurium and Monophasic Variant 4,[5],12:i- Isolated from Salami and Human Patients. Journal of Food Protection, v.80, n.4, p.632-639, 2017.

BAM - Bacteriological Analytical Manual. 8th Edition, Revision A, 2016.

BONARDI, S.; BRUINI, I.; BOLZONI, L. et al. Assessment of Salmonella survival in dry-cured Italian salami. International 
Journal of Food Microbiology, v.262, p.99-106, 2017.

BRASIL. Ministério da Saúde. RDC 12, de 02 de janeiro de 2001. Regulamento técnico sobre padrões microbiológicos para alimentos. Diário Oficial da União, Brasília, 2001.

BRASIL. Ministério da Agricultura, Pecuária e Abastecimento. Instrução Normativa 62, de 26 de agosto de 2003. Métodos microbiológicos para análise de alimento de origem animal e água. Diário Oficial da União, Brasília, 2003.

BRASIL. Ministério da Agricultura, Pecuária e Abastecimento. Manual de Métodos Oficiais para Análises de Alimentos de Origem Animal. Brasília: MAPA, 2017, $140 \mathrm{p}$.

CDC - Centers for Disease Control and Prevention. Reports of Selected Salmonella Outbreak Investigations. Disponível em: https://www.cdc.gov/salmonella/outbrea ks.html. Acesso em 04 de janeiro de 2019.

CARRASCO, E.; MORALES-RUEDA, A.; GARCÍA-GIMENO, R.M. Crosscontamination and recontamination by Salmonella in foods: A review. Food Research International, v.45, n.2, p.545-556, 2012.

CHEN, T.L.; THIEN, P.F.; LIAW, S.C. et al. First report of Salmonella enterica serotype Panama meningitis associated with consumption of contaminated breast milk by a neonate. Journal of Clinical Microbiology, v.43, n.10, p.5400-5402, 2005.

CHITRAKAR, B.; ZHANG, M.; ADHIKARI, B. Dehydrated foods: Are they microbiologically safe? Critical Reviews in Food Science and Nutrition, v.19, p.1-12, 2018.
CHOUDHURY, S.A.; BERTHAUD, V.; WEITKAMP, J.H. Meningitis caused by Salmonella Panama in infants. Journal of the National Medical Association. v.98, n.2, p. 219-222, 2006.

COLELLO, R.; RUÍZ, M.J.; PADÍN, V.M. et al. Detection and Characterization of Salmonella Serotypes in the Production Chain of Two Pig Farms in Buenos Aires Province, Argentina. Frontiers in Microbiology, v.9, n.1307, 2018.

EFSA - European Food Safety Authority. Report of the task force on zoonoses data collection on the analysis of the baseline survey on the prevalence of Salmonella in slaughter pigs, Part A. The EFSA Journal, v.135, p.1-111, 2008.

ELLAJOSYULA, K.R.; DOORES, S.; MILLS, E.W. et al. Destruction of Escherichia coli O157:H7 and Salmonella Typhimurium in Lebanon bologna by interaction of fermentation $\mathrm{pH}$, heating temperature and time. Journal of Food Protection, v.61, n.2, p.152-157, 1998.

GORMLEY, F.J.; LITTLE, C.L.; GRANT, K.A. The microbiological safety of readyto-eat specialty meats from markets and specialty food shops: a UK wide study with a focus on Salmonella and Listeria monocytogenes. Food Microbiology, v.27, n.2, p.243-249, 2009.

GOTTARDO, E.T.; VIANA, C.; BARCELLOS, V.C.; ZANETTE, C.M.; BERSOT, L.S. Embutidos cárneos fermentados artesanais como veículos de micro-organismos patogênicos de importância para a saúde pública. Boletim do Centro de Pesquisa e Processamento de Alimentos, v.29, n.1, p.97-102, 2011. 
GOUNADAKI, A.S.; SKANDAMIS, P.N.; DROSINOS, E.H. et al. Microbial ecology of food contact surfaces and products of small-scale facilities producing traditional sausages. Food Microbiology, v.25, n.2, p.313-323, 2008

HALD, T.; WINGSTRAND, A.; SWANENBURG, $M$. et al. The occurrence and epidemiology of Salmonella in European pig slaughterhouses. Epidemiology and Infection, v.131, n.3, p.1187-1203, 2003.

KICH, J.D.; SCHWARZ, P.; SILVA, L.E. et al. Development and Application of an Enzyme-Linked Immunosorbent Assay to Detect Antibodies against Prevalent Salmonella Serovars in Swine in Southern Brazil. Journal of Veterinary Diagnostic Investigation, v.19, n.5, p.510-517, 2007.

$\mathrm{KICH}$, J.D.; COLDEBELLA, A.; MORÉS, $\mathrm{N}$. et al. Prevalence, distribution, and molecular characterization of Salmonella recovered from swine finishing herds and a slaughter facility in Santa Catarina, Brazil. International Journal of Food Microbiology, v.151, n.3, p.307-313, 2011.

KUHN, K.G.; TORPDAHL, M.; FRANK, C. et al. An outbreak of Salmonella Typhimurium traced back to salami, Denmark, April to June 2010. Eurosurveillance, v.16, n.19, p.ii, 2011.

LUZZI, I.; GALETTA, P.; MASSARI, M. et al. An Easter outbreak of Salmonella Typhimurium DT 104A associated with traditional pork salami in Italy. Eurosurveillance, v.12, n.4, p.E-11-2, 2007.

MARTIN, B.; GARRIGA, M.; AYMERICH, T. Prevalence of Salmonella spp. and Listeria monocytogenes at Small-Scale Spanish Factories Producing Traditional Fermented Sausages. Journal of Food Protection, v.74, n.5, p.812-815, 2011.

MOREIRA, P.L.; LOURENÇÃO, T.B.; PINTO, J.P.A.N. et al. Microbiological quality of spices marketed in the city of Botucatu, São Paulo, Brazil. Journal of Food Protection, v.72, n.2, p.421-424, 2009.

NIGHTINGALE, K.K.; THIPPAREDDI, H.; PHEBUS, R.K. et al. Validation of Traditional Italian-Style Salami Manufacturing Process for Control of Salmonella and Listeria monocytogenes. Journal Food Protection, v.69, n.4, p.794-800, 2006.

PEREA-SANZ, L.; MONTERO, R.; $B E L L O C H$, C. et al. Nitrate reduction in the fermentation process of salt reduced dry sausages: Impact on microbial and physicochemical parameters and aroma profile. International Journal of Food Microbiology, v.282, p.84-91, 2018.

REIJ, M.W.; DEN AANTREKKER, E.D.; ILSI Europe Risk Analysis in Microbiology Task Force. Recontamination as a source of pathogens in processed foods. International Journal of Food Microbiology, v.91, n.1, p.1-11, 2004.

SAGOO, S.K.; LITTLE, C.L.; GREENWOOD, M. et al. Assessment of the microbiological safety of dried spices and herbs from production and retail premises in the United Kingdom. Food Microbiology, v.26, n.1, p.39-43, 2009.

SCHWARZ, P.; CALVEIRA, J.; SELLA, A. et al. Salmonella enterica: isolation and seroprevalence in swines slaughtered in Rio Grande do Sul. Arquivo Brasileito de Medicina Veterinária e Zootecnia, v.61, n.5, p.1028-1034, 2009. 
SILVA, M.C.; FARIA, G.S.; DE PAULA, D.A.J. et al. Prevalência de Salmonella sp. em suínos abatidos no Estado de Mato Grosso. Ciência Rural, v.39, n.1, p.266-268, 2009.

SOSPEDRA, I.; SORIANO, J.M.; MAÑES, J. Assessment of the microbiological safety of dried spices and herbs commercialized in Spain. Plant Foods for Human Nutrition, v.65, n.4, p.364-368, 2010.

TOLDRA, F. Lawrie's Meat Science. 8 ed. Duxford, UK :Woodhead Publishing, 2017, 732 p.

ZHANG, G.; HU, L.; POUILLOT, R. Prevalence of Salmonella in 11 Spices Offered for Sale from Retail Establishments and in Imported Shipments Offered for Entry to the United States. Journal of Food Protection, v.80, n.11, p.1791-1805, 2017.

ZOCCHE, F.; BARCELLOS, V.C.; BERSOT, L.S. Microrganismos indicadores e Salmonella sp. em salames produzidos e comercializados na região oeste do Paraná. Revista brasileira de Tecnologia Agroindustrial, v. 5, n.1, p.336-345, 2011.

ZWEIFEL, C.; STEPHAN, R. Spices and herbs as source of Salmonella-related foodborne diseases. Food Research International, v.45, n.2, p.765-769, 2011. 